\title{
A.A. Borisenkov
}

\section{New Research Paradigm in Political Science}

\begin{abstract}
The subject of the article is the paradigm that presents an innovative approach to studying politics in the context of political integrity and the relevant political system. This is a paradigm that defines the nature and direction of research on politics. Its content and conclusions are based on research into the structure of the political reality. This research is aimed at discovering the components of this reality, and providing an understanding of their details and purpose, and of their interconnections and interdependencies. As a result, we provide conclusions on the requirements for further analysis of the systematic elements of political reality, for the future systematization of existing political knowledge, and the development of theory. The methodology of the research is based upon understanding the essence and existence of different types of politics, and the place and role of politics in society. This methodology consists of a number of ideas. One of these is that politics is considered to be a specific public activity, which is created by, functions as part of, and plays a leading part in, social management. The leading part that politics plays is to define the direction of executive activities, which influences social management itself and the activities of the managing instrument. Another important concern is the analysis of how a specific type of politics can, by its very nature, develop the political system. This refers to government policy, which, as an independent component within the structure of a government, represents a significant issue when research of any political reality is carried out. This is an element of politics that has been developed by a government over a long period of time, so that, today, it is characterized by a high level of complexity and development. It is in this context that certain laws of politics are being recognized and interpreted. Therefore, government policy, being an instrument of management, provides a fundamental back-drop to any research into politics. The third idea relates to the development of the political structure, which influences the direction of political analysis. It is a well-known fact that the division of a whole entity into parts, and the study of the separate elements, is a universal principle of learning about anything. This is the principle that is used in many different sciences; and its importance has been repeatedly demonstrated in research. This is the principle that provides the basis for explaining the structure of political reality, and, above all, that defines the logic of political theory development, and, therefore, of the
\end{abstract}

BORISENKOV Alexander Alexandrovich - Doctor of Sciences in Philosophy, Expert, State University of Management.

109542, Russia, Moscow, Ryazanskiy prospect, 99

[alex.borisenkov@mail.ru] 
whole study of politics. The division of politics (i.e. political reality) into separate components is a unique philosophical technique that creates the necessary conditions for the understanding of politics, and, as a result, contributes to the further systematization of political knowledge. The innovation of the research lies in the way that it reveals the structure of political reality, as represented by a political system that is characterized by components that are independent, yet at the same time interconnected. The political system divides political reality into its component parts, which are united, directly connected and correlated, but also different from one another.Analysis of the political system recognizes three elements of political reality, which relate to the most common political phenomena and represent methods due to their contents. These are: political life, political influence and political culture.Political life relates to the independence of politics; it is part of the functionality of the political organism. Politics cannot exist and fulfill its purpose without the functionality of its organism. Therefore, political life, as with any life, is connected with the political organism. Political life may be defined as an aspect of political reality that is based on the functionality of the political organism. In fact, the essence of political life is associated with the structure of the relevant political organism, and is defined by the organism's components. For instance, under a democratic regime, political life consists of, first of all, a number of political relationships, above all the relations hip between the government and the opposition, which are the fundamental components of the political organism. Political life also consists of the interconnections that constitute the system of this organism (the political system). The purpose of political life, as a component of political reality, includes providing a medium for the formation of polycies. Based on the existence, and the functionality, of political life, decisions are made, and thus conditions are created for the role of the politicswithin the social management system, i.e. pre-formation of political influence. This is its specific role within the political structure.Another aspect of political reality is political influence, which relates to the political purpose of the social management tool. Unlike political life, political influence is affected by the overall mission of the politics. Political influence is derived from the adoption of government resolutions, and relates to the fact that, through these resolutions, executive actions and the whole essence of management are defined. Political influence is a component of political reality that defines the direction of executive activities.Political influence as a term, and as an entity, has not been studied in the political studies, and that is why it requires special consideration. It devours the instrument and the direction of this influence and recognized by means of more frequent phenomena such as, for instance, the political regime and the political process. When defining the direction of executive activities, political influence is the main instrument of social management, and one on which other functions within the system depend. Because of the part that political influence plays, it is characterized as a primary type of political reality.Another element of the political structure is political culture, which influences the way in which political power is used, and thus the way in which political life and political influence are implemented. Basically, this refers to the order of implementation, which is defined through the means by which political power is used, and represented by protocols for adopting government resolutions. Political culture is an aspect of political reality that is associated with the rules for the adoption of government resolutions. This aspect of political reality may be characterized as being technological.The essence of each of the above elements of political reality is defined through the combination of other, more specific, political ele- 
ments, which together form particular groups. Each of these elements is related solely to «its own» group of the political elements. Political life develops as a function of influences which include political relations and the political system, which characterize the functionality of the political organism. Political influence is implemented through the political regime and the political process, which define the instrument and its means of influence. Finally, political culture is defined by the means by which political power is used, and is represented by protocols for the adoption of government resolutions. For instance, democratic political culture is associated with the adoption of government resolutions through polling which is based on the majority principle. As a result, it is noted that the new research paradigm can be used in the study of a number of aspects of political science, which are fundamental to political knowledge. The new paradigm also lays the foundations for the establishment of relationships and hierarchy between them. Keywords: politics, political science, political theory, paradigm, political reality, political integrity, political structure, political life, political influence, political culture.

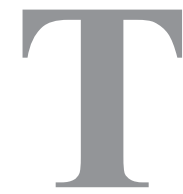

he paradigm in question represents a special approach to the study of political reality, and is based upon a perception of political integrity and the relevant political structure (i.e. the structure of the political system). Using existing political knowledge, this approach defines the nature and the direction of research into politics, and acts as an important influence on the scientific process. A more detailed account of this approach appears in the original work ${ }^{1}$.

This paradigm, and the conclusions derived from it, are implemented in the context of the political structure, which in turn reflects the structure of the political reality. This research establishes the general components of this reality, an understanding of their purposes and specifications, and their interconnections and interdependencies. As a result, we derive recommendations for priorities for further analysis of the systematic elements of the political reality, and for the systematization of existing political knowledge and the development of a theory. The following are a few examples of perceptions of political reality.

\section{Perception of the structure of political reality}

The issue of political structure is actually not well developed in the political science literature.

\footnotetext{
${ }^{1}$ Borisenkov, A.A. Political Science. The Political Theory. Moscow: 2013.
}

If we consider existing views on this issue, then it is necessary to note that, first of all, they do not constitute a large body of literature; second, the views vary, due to the degree of subjectivity involved; and third, they are not always clear or reasonable. One of the reasons for this may be the fact that there are different types of politics involved (i.e. types of politics as a management tool). As a result, the analysis of a specific political type, in order to define the structure in question, becomes problematic.

In this case, it is government politics which are in question, and these represent a special political type, constituting a fairly independent element of state management. This is a type of politics that has developed over a long period of time, and is now characterized by a high level of complexity and development. It is in this context that certain laws of the politics are being recognized and interpreted. As a result of research on government policy, which is a management instrument, fundamental principles for research into politics have been established. In particular, studying the complexity and development of government politics within the framework of a modern democracy brings us closer to understanding the political structure, and also allows us to understand the political reality (political integrity).

From the methodological point of view, the issue of political structure plays an important part in political science, because it defines the 
whole process of political research. Politics as a political science subject is, above all, associated with the establishment of a structure that creates the necessary conditions for further political analysis. It is a well-known fact that the division of a whole entity into parts, and the study of the separate elements, is a universal principle of learning about anything. This is a principle which is used in many different sciences; and its significance has been repeatedly demonstrated in research. This is the principle that provides the basis for explaining the structure of political reality, and, above all, that defines the logic of political theory development, and, therefore, of the whole study of politics. Moreover, the division of the essence of political reality into separate components is a unique philosophical technique; and if it is considered in the context of today's political science, this division is an innovative technique that creates the necessary conditions for the further theoretical understanding of politics, which can facilitate the development of political theory.

It is noteworthy that few political researchers choose to study the matter of political structure. A number of special editions that focus on specific categories within politics do not include the term «political structure» at all. Researchers who try to investigate this issue do not define the political structure itself, but instead list the elements of the political reality straight away. Such attempts are intuitive in nature; therefore, they are not very reliable, and actually distract a researcher from the political structure. This is illustrated in the following example.

One political science study that attempted to discover such a structure states «The political structure consists of a number of completely different components: people, organizations, relations, actions, programs and emotions that set the nature and the purpose of these actions. But the whole variety of the components may be generalized into three main groups". These groups are named as follows: objects of the

${ }^{1}$ Demidov, A.I. \& Malko, A. V. The Political Science in Questions and Answers. Moscow: 1998. p. 54 politics, subjects of the politics and resources of the politics, which are considered by the authors of this work as the elements of political structure.

Among existing views on the structure in question, this opinion is the least prosperous. This is because the named components (objects, subjects and resources) are of different origin. Therefore, they lack the necessary degree of unification that is necessary for the parts to make up the whole entity. Therefore, they are not structural elements of political reality, and, consequently, they do not define the political essence. For instance, it is unclear how objects and subjects may be included in politics. It is rather obvious that they are not political entities at all. They only act as specific factors in the formulation of policy; and, even then, they are just external factors in this context.

Another approach to the interpretation of political structure also emphasizes three elements of politics. One of them is political organization, which is, in the author's opinion, the combination of institutions such as parties, lobbies, political movements, mass media, trade unions, etc., as well as the representative and executive authorities of government. Another element of politics is a special type of awareness, but the author does not define it clearly enough. He states that «The essential elements of the political structure are non-institutional elements that reflect the whole array of the ideal events (forms of awareness)" ${ }^{\prime 2}$. The author considers such events to include programmes, ideologies, utopias, myths, and "other ideal images». It may be assumed that the author is referring to political awareness, which is usually interpreted in this way within political science. Some researchers do not «overthink» this matter, and characterize political awareness as being an element of political structure. ${ }^{3}$ Finally, the third element of this structure is named political relations, which are defined as

\footnotetext{
${ }^{2}$ Solovyev, A.I. The Political Science. The Political Theory. The Political Technology. Moscow: 2010, p. 40.

${ }^{3}$ Smirnov, G.N., Petrenko, E.L., \& Bursov, A.V. The Political Science. Lectures. Moscow: 2011, p. 122.
} 
«the special features of the activities aimed at the state power». ${ }^{1}$

Let us compare this version with another, more presentable attempt, (in terms of the number of proposed political components), to define political structure. This alternative defines the elements of this structure as follows: political power, political organization, political relations, political subjects, political awareness and political culture ${ }^{2}$.

Both versions have an approach that is basically similar, which also includes rational aspects. Nevertheless, they are still unacceptable. The reason is the lack of grounds for the definition of the elements of political structure. In other words, the authors fail to define the political structure, and do not state the criteria for the establishment of structural elements. Yet, these attempts represent a rather complicated approach to the resolution of this matter, and deserve further examination. But first, we must define what political structure is, and its elements.

\section{Political structure and its elements}

We refer to the general perception of any structure. For instance, it is known that «structure» (Latin: structūra) is the configuration and connection of the components of anything, i.e. design ${ }^{3}$. Political structure may be interpreted as an element of the formation of political reality, which reflects the presence of relatively independent, and at the same time interconnected, parts of the political integrity. If we are to emphasize the special features of the political components of political integrity (political reality), then they must be in accordance with the following requirements. First, they must be well-separated from one another; second, they must be interconnected; third, they must be of the same nature; and fourth, they must relate to one another, i.e. be of the same nature, but together define

\footnotetext{
${ }^{1}$ Solovyev, A.I. The Political Science. The Political Theory. The Political Technology. Moscow: 2010, p. 40.

${ }^{2}$ Mukhaev, R. T. The Political Science. Moscow: 2007, p. 18-19

${ }^{3}$ Dictionary of foreign words. Moscow: 1989, p. 488
}

the whole meaning of the political reality (political essence). Bearing this in mind, the following definition may be proposed: political structure is the division of political reality into internal elements, which are directly connected and correlated with one another, and at the same time are different political events that together cover the whole essence of political reality. Referring to this definition and the highlighted criteria, we may now analyze existing views, and establish the true elements of political structure.

To recap, different elements of political reality, in one way or another, are defined in political science. However, their internal union and direct interconnection are not mentioned or defined. As a result, any definition of political structure, provided by the political science literature, is not convincing enough. Therefore, the idea of the union, and the direct connection, of the structural elements of political reality must be particularly emphasized. Accordingly, the unification of different political entities, according to the principles of public knowledge, may involve only one relevant type of social activity, namely political activities. They are a particular type of social activity, and are the starting point for the appearance and development of all political events. Therefore, political activities are what unify these events.

So, what are the elements of political structure?

Let us return to the approach in question. As stated in the above definitions of political structure, it is noticeable that the elements defined, even though connected with politics, are not of the same origin; therefore, not all of them are associated with political reality. First of all, this concerns the subject of the politics, which has already been mentioned. In addition, it may be emphasized that the special nature of politics as a social phenomenon is defined, not by the subjects, but by the connections between subjects in the process of the use of the political power, which are shown through particular actions and functions. The people themselves, the subjects of politics, cannot be an element of the political structure, nor an element of political reality. They are only 
the creators of policy, the executors of political activities and the makers of political connections.

There is one factor that is not an element of the political structure, nor a component of the nature of politics; in fact, it is not at all associated with political characteristics. This factor is political awareness. As with the origin of any social awareness, it is not a part of social reality, which consists of the different connections between people. Philosophical thought has determined that society and awareness (i.e. social awareness) are two very distinct, though interconnected, realities: material and idealistic. Society, (while politics is a social phenomenon), is a result of the practical and material activities of people, whereas political awareness is a result of spiritual activities, and is not at all a social phenomenon. This means that politics and political awareness also have different origins: politics results from political (i.e. practical) activities, and political awareness is the result of cognitive (i.e. spiritual) activities. Obviously, they cannot be of the same nature.

Another important consideration is political culture. It is a specific aspect of political reality, a special component of the political sphere; and, at the same time, it is one of the most important influences on the mechanisms of politics. In contrast to political awareness, which is only a reflection of political reality, political culture is part of the very nature of political reality, being responsible for its means of implementation, and thus being part of its existence. Political culture reveals a certain portion of that reality, and is manifested through political activities. Since politics is public, and therefore a material entity, then political culture is a material culture ${ }^{1}$.

Attempts are often made to associate political culture with consciousness and behavior, by, for instance, attaching meaning to the results of a study of political, or typical behavioral, activity. Use is often made of political knowledge, views, opinions and «psychological orientation», as indicators of political culture. As a result, very different entities are bound together, e.g. po-

\footnotetext{
${ }^{1}$ Borisenkov, A. A. Political Science. The Political Theory. Moscow: 2013, p. 289-303
}

litical (public) entities, and those of a cognitive (spiritual) nature which are formed with regard to policy. Moreover, political culture, as a particular type of culture, is mixed in with a different type of culture, behavioral culture, which contradicts the principles of cognition. Thus, the definition of political culture, and political reality in general, become distorted.

Next, one must acknowledge the fact that political reality involves political relations. These relations are determined by political activities, and they reflect the various ways of using political power. They are represented by, and manifested in, the actions of people in the political process. Political relations are a true political entity. However, they possess special features. For instance, they are components of political life, which characterizes political reality and is also included in its meaning. This means that political relations are, above all, elements of its structure.

Political life, on the other hand, in contrast to political relations, appears to be a more general political entity, that covers these relations. Political life and political relations are different in terms of their meaning. Therefore, as a structural component of political reality, political life, which includes political relations, should be considered first. As one of the most prominent political entities, it covers other, more specific, political phenomena. In addition, political life is related to political culture, i.e. they are the most visible, and are therefore correlated, political entities, each having its own meaning. Being very different, and, at the same time, the most prominent political entities, they represent different aspects of political reality, while political relations reveal the meaning of one of these aspects. Political relations are not component of political structure.

The next political entity to be considered is political organization. If we present this as being a part of the political structure, it must meet the relevant criteria to be a true political entity, and reflect the essence of politics. However, political organization as an entity is not at all a part of political reality; it only creates certain preconditions for its implementation. Any organization is an entity, and a result of the establishment of a 
certain order necessary for the implementation of such actions. But the organization itself is not a component, as the structure of an entity is not a part of this entity. Therefore, political organization that reflects the implementation of political reality should not be considered as a component of this reality.

However, there is another meaning of the term «political organization», which is most commonly used in the political science literature. A «political organization» usually means an association of citizens that desire to acquire political power and call themselves a political party, or consider the political organization as a combination of various civic associations and institutions.

Such an interpretation of a political organization, although well established in political science, requires clarification. Due to the fact that any constitutionally defined association of citizens, including a political party, is, above all, an element of civic society, it is basically a civic institution. This means that a political party, as well as any other civic association, is not a political organization, but a civil organization, which, above all, creates a precondition under which citizens can compete for political power in a modern democratic state. Possibly, the next statement may, ordinarily, seem absurd: but there is nothing political about a political party, or any other civil institution. Political parties and other associations of citizens are neither a political component (i.e. component of political reality), nor a political institution, as they are often called. Criteria for political institutions will be considered separately ${ }^{1}$.

Finally, another possible element of political structure, that was first put forward by one of the authors of the «analytical approach», is political power. Even though the assessment of the significance of this phenomenon is correct, we must still regard this view as being false. Political power, absurd as this sounds, is neither a part of the political structure, nor is it part of the political reality. Unlike the true political components that constitute political reality, political power is not

\footnotetext{
${ }^{1}$ Borisenkov, A.A. Political Science. The Political Theory. Moscow: 2013, p. 198-211
}

generated by political activities, and is therefore not related to political events. On the contrary, political power exists before political activities; it constitutes a specific social element, because of which activities occur, and the political reality becomes possible. Consequently, political power is a special precondition of the political structure. In contrast to politics and the individual manifestations of politics, political power has a different origin, and requires special analysis ${ }^{2}$.

Thus, existing perceptions of political structure, in the political science literature, are of a contradictory nature, which is mainly due to the insufficiency, or even lack of, a basis for its interpretation. The analysis of the whole development of political reality shows that the diverse range of political entities which contribute to its meaning can be narrowed down to the three most commonly cited entities - which are also the most commonly correlated. These include politics, political influence and political culture. In contrast to the more specific political entities (e.g. political relations), they form the main components of political reality. These are all fairly different, but simultaneously interconnected, and cover all of its meaning. They are components of political reality, and are therefore elements of the political structure. Political reality is made up of very general political phenomena that define different aspects of this reality, and which are elements of political structure. The identification of such phenomena has become possible due to the development of politics as a specific entity, (case study of government politics), and the development that acquired its representation and expression in the formed political structure and the establishment of political integrity. These phenomena are defined, briefly, in the following sections.

\section{Aspects of political reality}

The term "political life» is not considered in sufficient detail in the political science literature, even though the term is commonly used. There are a number of approaches to the interpretation

\footnotetext{
${ }^{2}$ Borisenkov, A. A. Political Science. The Political Theory. Moscow: 2013., p. 91-104
} 
of this concept. At the same time, the diversity and complexity of political life are duly noted; and it is stated that this term is used for the definition of different political and democratic processes ${ }^{1}$.

Political life, as a concept, is associated with the independence of political existence, and it is related to the way in which the political organism functions, i.e. it is a specific feature of political reality. Every organism is a combination of functions, and is based on their interconnections as a system. In structure, an organism comprises, first of all, a series of functions, which are associated with separate organs, and which act as independent life-forms within the life of the organism. Secondly, there are their interconnections as a system, which are associated with the general life of the organism. The political system cannot exist and fulfill its purpose without relying on the life of the organism. Therefore, political life, as any life, is associated with its corresponding organism. Political life accompanies the existence of the political organism, and does so throughout its process of development. Political life may be defined as a type of political reality which is associated with the functioning of the political organism.

The meaning of political life is determined by the structure of the relevant political organism, and is developed by the components of which it consists. For example, political life in democratic conditions consists of, first, various political relations and, above all, the relations between leadership and opposition, which are the basic functions of the political organism. Secondly, their interconnections constitute the system of this organism (i.e. the political system).

Moreover, political relations, as political entities, are part of, and components of, political reality. They are not, however, elements of the political structure, as they are elements of the structure of political life. They act as separate political entities, in relation to which political life acts as a general political phenomenon that creates a type of political reality. As separate political constructs,

\footnotetext{
${ }^{1}$ Demidov, A.I. The Political Life as the Instrument of Human Measurement of the Politics // Polis: 2002. \# 3
}

political relations are not directly connected with other, equally separate, political entities, such as the political regime or the political process. The latter represents a different type of political reality, called «political influence».

The importance of political life as an aspect of political reality relates to the fact that it contains a mechanism for the formation of the politicies, (i.e. the mechanism of the executive decision-making process). Based on the functioning of the political organism, (and due to the existence of political life, the adoption of executive resolutions and the creation of conditions which enable social control), the conditions for political influence are established. In this way, political life constitutes the precondition for political influence, and can therefore be considered as an initial version of political reality. This is its special place, and its role as an element of political structure.

Another aspect of political reality, and an element of political structure, is political influence, which characterizes the purpose of politics in terms of social control. In contrast to political life, political influence reveals the administrative objectives of policy. Political influence is a general political phenomenon that is brought about by the adoption of executive resolutions. The course of executive activities is determined by these resolutions, as are the essence of social control and the essence of the activities of the administrative body where policies were formed. Political influence is a type of political reality, which defines the course of executive activities.

Political influence, as an entity, has not been studied in the political science literature. This influence has its own mechanisms, and develops through such common political entities as the political regime and the political process. Political influence plays the leading role in establishing social control, and the implementation of other functions is based upon this. This aspect of political influence provides the basis for considering it to be the leading type of political reality.

There is a final element of political structure, and type of political reality, which determines how political power is exercised, and therefore how political life and political influence are imple- 
mented. This is the mechanisms of political life and political influence, which are represented and manifested in the specific way in which political power is exercised, i.e. the particular rules of the state decision-making process. This component of politics is called political culture. Political culture is an aspect of political reality, which consists of the rules for the state decision-making process.

For instance, the parliament, as a political institution, symbolizes the democracy that it represents, and thus becomes the carrier of the democratic order in the exercising of political power, and the democratic guidelines for the adoption of executive resolutions. As a result, the parliament becomes a carrier of the democratic political culture, i.e. the political culture that has developed under the direct influence of the democracy. In contrast to the parliament, the institution of the head of state, when associated with the activities of one person, may be considered to be the carrier of authoritarian political culture. Such culture truly develops if the head of state is politically authorized and is at the same time outside of democratic (national) control. Political culture is a type of political reality which may be described as technological.

These are the three most common political entities that are used to describe different types of political reality, and represent elements of political structure. It is noteworthy that the essence of each of them determines other, more closely defined, political entities; and by being a part of these types, they form the corresponding groups. At the same time, each type of political reality is directly related only to its «own» group of political events. For example, political life is revealed through phenomena such as political relations and the political system, which characterize, by their operation, the functioning of the political organism, and this includes the mechanisms of the executive decision-making process. In contrast, political influence is imposed by the political regime and the political process, which reveal the mechanism and the course of this influence. Finally, the exercising of political power and the relevant decision-making processes represent political culture. For example, democratic po- litical culture involves the adoption of executive resolutions by means of a poll, and based on the majority rule.

Let us emphasize the fact that, in this case, the proposed version of political structure is in accordance with the above definition, taking into account the criteria of analysis used to derive this definition. According to these criteria, the featured elements of political structure, which are political life, political influence and political culture, are fairly independent, but at the same time interconnected, components of political reality. They are connected by means of the essence of the policies that are represented by executive resolutions; and, therefore, they define one another. Secondly, they possess the internal unity brought about by the political activities that underlie all political entities. Thirdly, each of them plays a specific part in the essence of political reality, which emphasizes their well-defined distinctions. Fourthly, they are the most commonly defined political entities, and correlate with one another and cover the entire essence of politics.

Moreover, these political phenomena provide the basis for the classification of all the other, more narrowly defined, political entities, divide them into groups according to their laws of implementation and suggest an agenda for further research. When dividing politics into its constituent parts, general political entities define the course of political research, which might focus on theories of political life, political influence and political culture. It opens new research questions of the politics sience as well as the basis for a new structuring and systematizing of existing political knowledge. This will lead to a different vision of political theory.

Thus, a new research paradigm brings new opportunities for political science. It creates a different «framework» for the existing political science data. Using these data, the paradigm drives further systematization and ordering, as well as the formation of a completely different view of politics. It also encourages the reconsideration of political categories, which are the carriers of political knowledge, and creates conditions for the identification of the relationships between 
coordination and subordination. By establishing a landmark in political research by defining political structure, the paradigm sets out the future course of research into the different types of political reality. As a result, it encourages political science to seek a deeper understanding of the paradigm itself, and to further develop the relevant knowledge base.

At the same time, it is abundantly clear that modern political science may well combine alternative and competing approaches, to form a socalled conglomerate of new and existing scientific knowledge. In this case, conflict between the old and the new paradigms is inevitable, which indicates the occurrence of a new point of development in political science. The proposed paradigm also confirms the conclusion that science does not tolerate contradiction or uncertainty, and pushes political science towards further research. Meanwhile, there are a number of matters to be re- solved in modern political science. The proposed paradigm creates the conditions for overcoming issues in political science, helps clarify existing notions about politics, and encourages further reflection on them.

For instance, the explanation of political structure and the establishment of the main components of political reality both require a more detailed and separate study. At the same time, the starting point for political analysis is political life, in its various manifestations. The formation of perceptions of political life creates the precondition for further, deeper study of other important facets of political reality, political influence and political culture. This means that the analysis of political life is key in fully understanding the essence of politics. It can also act as a separate area of theoretical knowledge about political life, which can be the fundamental component of political theory.

\section{References}

1. Borisenkov, A.A. Political Science. The Political Theory. Moscow: 2013.

2. Demidov, A. I. The Political Life as the Instrument of Human Measurement of the Politics // Polis: 2002. \#3

3. Demidov, A.I. \& Malko, A. V. The Political Science in Questions and Answers. Moscow: 1998.

4. Mukhaev, R. T. The Political Science. Moscow: 2007.

5. Dictionary of foreign words. Moscow: 1989.

6. Smirnov, G.N., Petrenko, E.L., \& Bursov, A. V. The Political Science. Lectures. Moscow: 2011

7. Solovyev, A. I. The Political Science. The Political Theory. The Political Technology. Moscow: 2010

8. Almond G. [et al.] Comparative politics today: A world view. 7th ed. N.Y., 2000.

9. Almond G., Verba S. The Civic Culture Revisited: An Analytic Study. Boston, 1980.

10. Beyme K. von. Politische Theorie // Staat und Politik. Neue Hagen, 1995.

11. Gannel J. In Search of the Political Object Beyond Methodology and Transcendentalism // Ed. By J. Nelson. N.Y., 1983.

12. Leohold D., Stears M. Political Theory: Methods and Approaches. Oxford, 2008.

13. Frankfort-Nachmias Ch., Nachmias D. Research methods in the social sciences. Sth ed. N.Y., 1996.

14. Sil R., Katzenstein P. Beyond Paradigms. Analytic Eclecticism in the Study of World Politics. N.Y., 2010.

15. Stepan A. Arguing Comparative Politics. Oxford, 2001. 